\title{
Prevalence of dementia in African-Caribbean compared with UK-born White older people: two-stage cross-sectional study
}

\author{
Simon Adelman, Martin Blanchard, Greta Rait, Gerard Leavey and Gill Livingston
}

\section{Background}

Preliminary studies in the UK, all using screening instruments of unknown cultural validity, indicate that there may be an increased prevalence of dementia in African-Caribbean people, possibly related to vascular risk factors and potentially amenable to preventative measures.

\section{Aims}

To determine the prevalence of dementia in older people of African-Caribbean country of birth compared with their White UK-born counterparts.

\section{Method}

A total of 218 people of African-Caribbean country of birth and 218 White UK-born people aged $\geqslant 60$ years were recruited from five general practices in North London. Those who screened positive for cognitive impairment using a culturally valid instrument were offered a standardised diagnostic interview. Two independent assessors diagnosed dementia according to standard operationalised criteria.

\section{Results}

African-Caribbean participants were 2 years younger, and those with dementia nearly 8 years younger than their White counterparts. The prevalence of dementia was significantly higher in the African-Caribbean (9.6\%) than the White group (6.9\%) after adjustment for the confounders age and socioeconomic status (odds ratio $(\mathrm{OR})=3.1,95 \% \mathrm{Cl} 1.3-7.3$, $P=0.012$ ).

\section{Conclusions}

There is an increased prevalence of dementia in older people of African-Caribbean country of birth in the UK and at younger ages than in the indigenous White population. These findings have implications for service provision and preventive interventions. Further research is needed to explore the role of vascular risk factors and social adversity in the excess of dementia in this population.

\section{Declaration of interest}

None.
There are around 24 million people with dementia worldwide and that number is expected to double every 20 years to 81 million in 2040. ${ }^{1}$ Most research on dementia in Black populations is from the USA, where a number of studies have indicated that older African-American people may be at increased risk of developing dementia, with proportionally more vascular dementia than the White population. ${ }^{2-7}$ Older Black people in the UK differ from those in the USA in that generally they are first-generation immigrants. The largest of these groups are people of AfricanCaribbean descent. As for the first time in the UK many of this group have now reached retirement age it is important to investigate whether they are at higher risk of developing dementia; in order both to help understand the aetiology of the dementias and to identify preventative interventions. A recent systematic review found three small studies in the UK, all using screening instruments of unknown cultural validity, indicating that there may be an increased prevalence in this population, possibly related to vascular risk factors and potentially amenable to preventative measures. ${ }^{8}$ Such vascular factors may be expected to increase the rates of both Alzheimer's disease and vascular dementia. ${ }^{9}$ As a minority ethnic group, African-Caribbean people have experienced social adversity including socioeconomic deprivation, racism, poor social capital and living in areas of low ethnic density. The first of these adversities has been associated with hypertension ${ }^{10}$ and others with raised rates of mental illnesses at younger ages. ${ }^{11,12}$ The aim of this study was to test the primary hypothesis that the prevalence of dementia is higher in older African-Caribbean people than in their White UK-born counterparts.

\section{Method}

\section{Study design and setting}

The study was a two-stage, cross-sectional prevalence study. It was set in general practices in the North London Borough of Haringey that has a well-established African-Caribbean population. Haringey is the fifth most deprived borough in London and its residents are ethnically diverse, with approximately half coming from Black and minority ethnic (BME) communities (www.haringey.gov.uk).

\section{Study population}

We used single-stage cluster sampling to obtain a representative sample of people of African-Caribbean country of birth aged $\geqslant 60$ years old from across the borough. This was achieved by simple random sampling of all general practices in Haringey and using the selected practices' patient lists as sampling frames. Practices are now required to code their patients for self-assigned ethnicity. ${ }^{13}$

All people aged 60 years and over living in Haringey, either in their own homes or in 24-hour residential care were eligible to take part. We included participants living in residential care homes to obtain a representative, community-based sample. As many people with dementia live in residential care, to have excluded them may have lead to an underestimate of the prevalence of dementia. The African-Caribbean group comprised people who had migrated to the UK from a Caribbean island or Guyana. The White reference group comprised White people born 
in the UK. From each participating practice, all eligible AfricanCaribbean individuals were identified and invited to participate in the study. As there were potentially many more White participants, they were randomly selected from the same general practice lists until an equal number had been recruited.

From previous studies we estimated the prevalence of dementia in older African-Caribbean people to be approximately $15 \%$, whereas that in the general population is approximately $5 \%{ }^{1}$ To detect a difference between $5 \%$ and $15 \%$ with a power of $90 \%$ and at a significance level of $5 \%(P \leqslant 0.05)$, we calculated that a sample of 207 people would need to be screened in each group (STATA statistical software package, version 9 for Windows). Given a response rate of $70 \%$ based on previous similar surveys (60-90\%), it was expected that approximately 300 people would need to be contacted in each group.

\section{Stage 1: screening interview}

We carried out the screening interviews between March 2007 and October 2008. The interview lasted between 20 and 45 minutes. We collected information directly from the participant, or from a relative or carer for those with evidence of significant cognitive impairment. The interview included the following elements.

(a) A brief questionnaire containing basic personal and demographic details: age, gender, country of birth, years in UK, marital status, years of education. Two measures of social and economic status were included; the self-coded version of the National Statistics Socioeconomic Classification (NS-SEC) $)^{14}$ and home ownership (yes or no). The NS-SEC is a measure based on a combination of current or previous employment type and supervisory/managerial status. We also included home ownership, because a single measure of socioeconomic status based on employment could introduce bias, notably as the African-Caribbean community were invited to migrate to the UK to fill relatively low-skilled jobs.

(b) The cognitive screening test: we used a culturally valid version of the Mini-Mental State Examination (MMSE) with a cut-off at $<26$ in the African-Caribbean group. ${ }^{15}$ In the White reference group we used a standardised version of the MMSE because it has been shown to score similarly on measures of specificity and sensitivity to that of the AfricanCaribbean version when used with the same cut-off point. ${ }^{16}$

\section{Stage 2: diagnostic interview}

We asked those screening positive on the culturally valid versions of the MMSE to participate in a structured diagnostic interview with a family member, friend or carer.

We used the Cambridge Mental Disorders of the Elderly Examination (Revised) CAMDEX-R, which includes a cognitive assessment (CAMCOG), ${ }^{17}$ to generate the information required for the diagnosis of dementia according to the operational diagnostic criteria chosen for the study. The CAMCOG comprises sections that assess a number of cognitive domains including: orientation, perception, language, memory (recall, recent and remote memory), attention/concentration, calculation, praxis and executive functioning. The CAMCOG was shortened to exclude potentially culturally specific tests. The data generated retained enough information to allow for diagnosis according to operationalised criteria. No total score was calculated and no cut-off used to indicate dementia. We used performance in specific cognitive domains to supplement the clinical information and informant history in making the final diagnosis, in accordance with standardised criteria. As informants were not always available, it was sometimes not feasible to complete the whole assessment. We also scrutinised general practice records, and (for those who had them) records from the local old age psychiatric service for evidence of cognitive decline. We also obtained any recent pathology results, neuroimaging reports and other relevant physical investigations. One of the authors (S.A.) conducted a structured physical examination to elicit any physical signs associated with dementia and to identify physical illnesses that might account for cognitive impairment.

One of the authors (S.A.) then collated data from both the screening and diagnostic interviews and summarised them in a standardised format. Names and ethnicity were removed from the original interview proforma. Two raters (G. Livingston and M.B.), masked to the ethnicity of each participant, judged independently whether a diagnosis of dementia could be made, according to ICD-10 Research Diagnostic Criteria ${ }^{18}$ and DSM-IV-TR ${ }^{19}$ criteria. In instances where the raters did not agree, consensus was reached through discussion. They also specified the dementia subtype(s) or diagnosis of mild cognitive impairment. Mild cognitive impairment describes the transitional stage between normal functioning and dementia, when people have an acquired cognitive deficit that does not have an impact on their level of functioning. ${ }^{20}$ We employed the following widely accepted standardised diagnostic criteria, which have satisfactory psychometric properties for subclassification of the dementia diagnoses:

\section{(a) Alzheimer's dementia: ICD-10, DSM-IV and NINCDS- ADRDA $;^{21}$}

(b) vascular dementia: ICD-10, DSM-IV and NINDS-AIREN; ${ }^{22}$

(c) dementia with Lewy bodies: Revised DLB Consortium Criteria; ${ }^{23}$

(d) frontotemporal dementia: consensus criteria; ${ }^{24}$

(e) other dementia: type specified.

\section{Statistical analysis}

We used two-tailed tests throughout. In order to assess for selection bias, we compared the age, gender and ethnic distribution between potential participants who were contactable and those who were not and for those who agreed to participate and those who declined. We performed univariate analyses to compare the demographic characteristics and MMSE scores between the African-Caribbean and White UK-born participants. We used a level of $5 \%(P<0.05)$ as the significance level to identify potential confounders to include in the multivariate analysis. For univariate tests, parametric statistics were used where the data approximated a normal distribution (Pearson's skewness statistic $< \pm 1.0) .^{25}$ We performed chi-squared or Fisher's exact tests in order to compare proportions, and independent $t$-tests or Mann-Whitney $U$-tests to compare continuous and nonparametric data, as appropriate. We used binary logistic regression techniques for both screening and diagnostic status. Variables chosen for the final analyses included those under investigation (i.e. dementia status and ethnic group) and potential confounders as identified from univariate analyses. All potential confounders were entered into a logistic regression model using a stepwise approach, with screening status as the dependent variable. Ethnicity was entered at step one and all other variables that reached statistical significance on univariate analysis in subsequent steps, in order to assess their effect on the model individually. As the numbers of participants with dementia were relatively small, variables for which data were missing in more than $20 \%$ of participants with dementia were excluded from the final 
multivariate analysis, otherwise missing data were imputed using SPSS software.

\section{Results}

\section{Recruitment}

Of the 14 general practices approached, 5 participated. Figure 1 summarises recruitment paths into the study. Of the 876 people identified from the lists, 210 were excluded, as they were either ineligible when contacted or could not be traced at the telephone numbers given. In total, $666(76.0 \%)$ people were contactable and met the inclusion criteria, of whom 436 (65.5\%) participants completed the screening interview, comprising 218 in each ethnic group. Of these, $421(96.5 \%)$ lived in their own homes, the remainder in a residential care home.

\section{Participants $\boldsymbol{v}$. non-participants}

The participation rate did not differ between groups; 218/320 $(68.1 \%)$ in African-Caribbean v. 218/346 (63.0\%) in White people $\left(\chi^{2}=1.927, P=0.165\right)$. Participants were also similar to non-participants in gender and age; 260/436 (59.6\%) female participants v. $128 / 230$ (55.7\%) non-participants $\left(\chi^{2}=0.981\right.$, $P=0.322$ ); the mean age of participants was 72.8 (s.d. $=8.0) v$. 73.1 (s.d. $=8.9)$ years in non-participants, $(t=-0.421, P=0.67)$.

\section{Demographics}

African-Caribbean participants came from 11 Caribbean islands and Guyana. The majority were born in Jamaica $(n=120$, $55.6 \%)$. The African-Caribbean sample was younger than the White group with a mean difference of 1.9 years (95\% CI $0.4-$ 3.4). The age structures differed, with fewer African-Caribbean participants over the age of 80 years. The proportion of home ownership was lower in the White group (Table 1). A higher proportion of African-Caribbean participants were in lower NS-SEC categories. There was no difference in duration of education or gender distribution between ethnic groups. All participants spoke English as their first language.

\section{Screening interview}

The scores on both the standard and African-Caribbean versions of the MMSE ranged from 0 to 30 . The median value for all groups combined were 28 (interquartile range $(\mathrm{IQR})=26-29$ ) for the standard version and $29(\mathrm{IQR}=27-30)$ for the AfricanCaribbean version. The African-Caribbean participants performed less well on both tests than their White peers (Table 1). A total

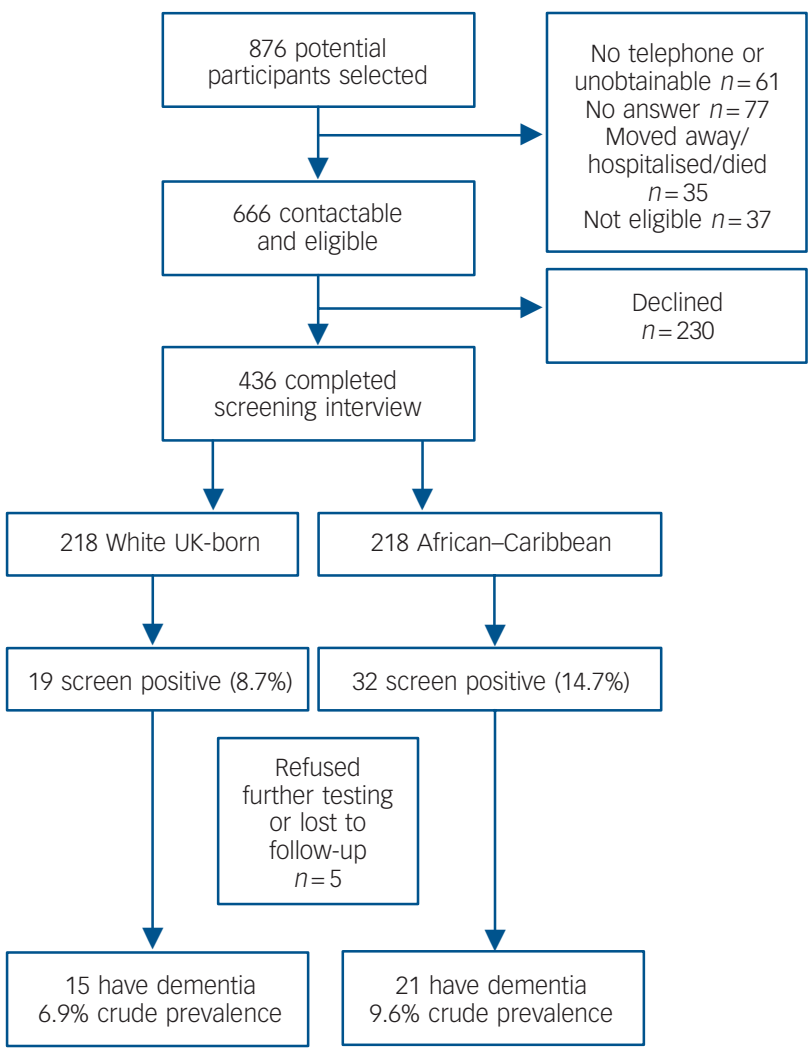

Fig. 1 Summary of recruitment.

of 51/436 (11.7\%) participants screened positive for cognitive impairment on their respective, culturally appropriate versions of the MMSE $\left(\chi^{2}=3.75, P=0.05\right.$, odds ratio $(\mathrm{OR})=1.80,95 \%$ CI 1.00-3.29). More than $28 \%$ of African-Caribbean participants would have screened positive on the standard MMSE (with the same cut-off) compared with just $8.7 \%$ of White participants $\left(\chi^{2}=2.74, P<0.001\right)$.

\section{Potential confounders}

The most likely confounders of the relationship between screening status and ethnicity from the literature were age and socioeconomic class. We used stepwise logistic regression with screening status as the independent variable. We entered ethnicity at step one $(\mathrm{OR}=1.82,95 \% \mathrm{CI} 0.99-3.29)$, followed by age at

\begin{tabular}{|c|c|c|c|c|c|}
\hline & $\begin{array}{l}\text { White UK-born } \\
\qquad(n=218)\end{array}$ & $\begin{array}{l}\text { African-Caribbean } \\
\qquad(n=218)\end{array}$ & $t$-test & $\chi^{2}$ & $P$ \\
\hline Age, years: mean (s.d.) & $73.7(9.1)$ & $71.8(7.1)$ & 2.528 & & 0.012 \\
\hline$>80$ years, $n(\%)$ & $58(26.6)$ & $28(12.8)$ & & $2.47^{\mathrm{a}}$ & $0.001^{\mathrm{a}}$ \\
\hline Male, $n(\%)$ & $90(41.3)$ & $86(39.4)$ & & 0.15 & 0.696 \\
\hline Married/co-habiting, $n$ (\%) & $80(37.7)$ & $100(47.2)$ & & 3.71 & 0.054 \\
\hline Years of education, median (IQR) & $10(9-11)$ & $10(9-11)$ & & - & - \\
\hline Home ownership, $n$ (\%) & $88(41.7)$ & $128(61.0)$ & & 1.56 & $<0.001$ \\
\hline Lower SEC (groups 4 and 5), $n$ (\%) & $115(55.3)$ & $154(74.7)$ & & 2.07 & $<0.001$ \\
\hline MMSE screening positive (standard version), $n$ (\%) & $19(8.7)$ & $62(28.4)$ & & 23.04 & $<0.001$ \\
\hline MMSE screening positive (African-Caribbean version), $n$ (\%) & $21(9.6)$ & $32(14.7)$ & & 2.80 & 0.094 \\
\hline
\end{tabular}


step 2 and socioeconomic class at step 3 . When age was controlled for, the association was highly significant $(\mathrm{OR}=3.56,95 \% \mathrm{CI}$ 1.64-7.70, $P=0.001)$ as was the relationship between age and social class and screening status.

\section{Diagnostic interview}

In total $94 \%(48 / 51)$ of those screening positive for cognitive impairment participated in the diagnostic interview but 2 participants (1 African-Caribbean) did not have enough information for a diagnosis. The remaining 6\% (3/51) refused diagnostic interview (all African-Caribbean). The dementia prevalence (according to at least one set of dementia criteria) was $15 / 218(6.9 \%, 95 \%$ CI 3.6-10.2) in the White group and 21/218 (9.6\%, 95\% CI 5.7-13.5) in the African-Caribbean group. The association between dementia and ethnicity was not significant $\left(\chi^{2}=1.09, P=0.03, \mathrm{OR}=1.44,95 \%\right.$ CI $\left.0.72-2.88\right)$. When participants with mild cognitive impairment were included, the prevalence increased to $17 / 218(7.8 \%, 95 \%$ CI $4.3-11.3)$ in the White group and $24 / 218(11.0 \%, 95 \%$ CI $6.9-15.1)$ in the African-Caribbean group $\left(\chi^{2}=1.32, P=0.25\right)$.

Table 2 shows the relationship of demographic and morbidity variables with dementia diagnosis. Table 3 shows the sociodemographic and morbidity profile of people with dementia in each ethnic group. The only difference was that African-Caribbean participants with dementia were significantly younger than their White counterparts (mean difference 7.8 years).

\section{Multivariate analysis}

The logistic regression analysis with dementia as the dependent variable included all 436 participants. We entered ethnicity at step 1 , age at step 2 and NS-SEC at step 3 (as the only two variables associated with dementia status on univariate analysis). Data on NS-SEC were imputed for the 22 participants for whom this was missing. African-Caribbean ethnicity, age and NS-SEC were all significant independent predictors of dementia. Those of UK African-Caribbean ethnicity were more likely to have dementia than their White UK-born comparators $(\mathrm{OR}=3.07,95 \% \mathrm{CI}$ 1.28-7.32). The odds of a dementia diagnosis also increased for every year increase in age $(\mathrm{OR}=1.20,95 \% \mathrm{CI} 1.13-1.265)$.

\section{Dementia subtype}

Of the 36 participants who were diagnosed with dementia, 26/36 $(72.2 \%)$ met the criteria for ICD-10 and 34/36 (94.4\%) for DSM-IV-TR diagnosis (Table 4). Although people fell into different categories according to which classification system was used, Alzheimer's dementia was the most common diagnosis overall and in each ethnic group according to all classification systems. Six did not meet the criteria for any of the dementia subtypes and were classified as 'dementia unspecified'. A further six met the criteria for more than one subtype. Only two participants were diagnosed with frontotemporal dementia and one with possible dementia with Lewy bodies. These three participants were also given a differential diagnosis of Alzheimer's dementia.

\section{Discussion}

\section{Main findings}

We found a higher prevalence of dementia in older AfricanCaribbean than White UK-born participants. In addition, for those with dementia, African-Caribbean participants were nearly 8 years younger than their White counterparts. Age was therefore a strong negative confounder of the relationship between dementia prevalence and ethnic group. Strikingly, the regression model predicted a 1.2 times increase in the prevalence of dementia for each year increase in age above 60 . This is equivalent to double the prevalence every 5 years as found in other studies, which would have included very few African-Caribbean people. ${ }^{26}$

African-Caribbean participants scored significantly better on the culturally sensitive 'African-Caribbean' version of the MMSE than the standard version, whereas White participants did equally well on both versions. This is consistent with the AfricanCaribbean version being 'culturally specific' rather than just being easier or less educationally biased, and supports the use of the African-Caribbean version of the MMSE in routine clinical practice.

\section{Strengths and weaknesses of the study}

This is the first cross-sectional study set in the UK, adequately powered to compare the prevalence of dementia between older

Table 2 The relationship of demographic and morbidity variables to dementia diagnosis

\begin{tabular}{|c|c|c|c|c|c|c|}
\hline & Dementia & No dementia & $t$-test & $U$-test & $\chi^{2}$ & $P$ \\
\hline Age, years: mean (s.d.) & $82.3(7.3)$ & $71.9(8.9)$ & 7.98 & & & $<0.001$ \\
\hline Male, $n(\%)$ & $16(44.4)$ & $160(40.0)$ & & & 0.271 & 0.603 \\
\hline Years of education, median (IQR) & $9(9-10)$ & $10(9-11)$ & & 2690 & & 0.001 \\
\hline Home ownership, $n$ (\%) & $16(50.0)$ & $200(51.4)$ & & & 0.024 & 0.878 \\
\hline Lower SEC (groups 4 and 5), $n$ (\%) & $27(93.1)$ & $242(62.9)$ & & & 1.44 & $<0.006$ \\
\hline
\end{tabular}

\begin{tabular}{|c|c|c|c|c|c|c|}
\hline & White UK-born & African-Caribbean & $t$-test & $U$-test & $\chi^{2}$ & $P$ \\
\hline Age, years: mean (s.d.) $n$ & $86.9(7.4) 15$ & $79.1(8.7) 21$ & 2.839 & & & 0.008 \\
\hline Male, $n / N(\%)$ & $9 / 15(60.0)$ & 7/21 (33.3) & & & 2.520 & 0.112 \\
\hline Married/co-habiting, n/N (\%) & $3 / 15(20.0)$ & $9 / 21(42.9)$ & & & 2.057 & 0.151 \\
\hline Years of education, median (IQR) $n$ & $9(9-10) 13$ & $9(9-11) 12$ & & 74.0 & & 0.852 \\
\hline Home ownership, $n / N(\%)$ & 5/15 (33.3) & $11 / 17(64.7)$ & & & 3.137 & 0.077 \\
\hline Lower SEC (groups 4 and 5), n/N (\%) & $11 / 13(84.6)$ & $16 / 16(100.0)$ & & & 2.644 & 0.104 \\
\hline
\end{tabular}


Table 4 Dementia subtype by ethnic group

\begin{tabular}{|c|c|c|}
\hline & \multicolumn{2}{|c|}{ Ethnic group, $n(\%)^{\mathrm{a}}$} \\
\hline & White UK-born & African-Caribbean \\
\hline \multicolumn{3}{|l|}{ Any dementia } \\
\hline ICD-10 & $10(66.7)$ & $16(76.2)$ \\
\hline DSM-IV-TR & $15(100.0)$ & $19(90.5)$ \\
\hline Either criteria & $15(100)$ & $21(100)$ \\
\hline \multicolumn{3}{|l|}{ Alzheimer's dementia } \\
\hline ICD-10 & $6(40.0)$ & $8(38.1)$ \\
\hline DSM-IV & $10(66.7)$ & $10(47.6)$ \\
\hline \multicolumn{3}{|l|}{ NINCDS-ADRDA criteria } \\
\hline Possible & $4(26.7)$ & 7 (33.3) \\
\hline Probable & $7(46.7)$ & 7 (33.3) \\
\hline Any criteria & $11(73.3)$ & $14(66.7)$ \\
\hline \multicolumn{3}{|l|}{ Vascular dementia } \\
\hline ICD-10 & $0(0)$ & $1(4.8)$ \\
\hline DSM-IV & $0(0)$ & $3(14.3)$ \\
\hline \multicolumn{3}{|l|}{ NINDS-AIREN criteria } \\
\hline Possible & $1(6.7)$ & $8(38.1)$ \\
\hline Probable & $0(0)$ & $0(0)$ \\
\hline Any criteria & $1(6.7)$ & $9(42.9)$ \\
\hline \multicolumn{3}{|l|}{ Dementia with Lewy bodies } \\
\hline \multicolumn{3}{|l|}{ DLB consensus } \\
\hline Possible & $0(0)$ & $1(4.8)$ \\
\hline Probable & $0(0)$ & $0(0)$ \\
\hline Any criteria & $0(0)$ & $1(4.8)$ \\
\hline \multicolumn{3}{|l|}{ Frontotemporal dementia, } \\
\hline Unspecified dementias & $4(26.7)$ & $2(9.5)$ \\
\hline \multicolumn{3}{|c|}{$\begin{array}{l}\text { DLB, dementia with Lewy bodies. } \\
\text { a. Percentage of all participants diagnosed with dementia in each ethnic group } \\
\text { respectively. }\end{array}$} \\
\hline
\end{tabular}

African-Caribbean and White UK-born people. It is therefore the largest study of dementia in the older UK African-Caribbean population. It is also the first prevalence study to have employed a culturally sensitive screening instrument for cognitive impairment in the African-Caribbean group. The original $\mathrm{MMSE}^{27}$ has been criticised as being strongly, culturally and educationally biased, performing poorly in some BME groups and usually overpredicting dementia. ${ }^{28}$ In the White reference group we used a standardised version of the MMSE. ${ }^{16}$ This was developed in an attempt to improve on the objectivity and intra-/interrater reliability of the original MMSE. The anticipated sample size was reached, and the response rate achieved was comparable with similar studies. The participants were demographically similar to the target population and this suggests no systematic response bias. We are unlikely to have missed many potential participants as $98 \%$ of the general population are registered with a general practitioner and the rates of registration for BME groups are at least as high as for the White population. ${ }^{29,30}$ We do not know, however, whether all general practice patients were coded for ethnicity. It might be that those who were less well and attended the surgeries were more likely to be coded in contrast to the most ill and housebound who did not attend surgery. Nevertheless, this should be similar for both ethnic groups.

The diagnoses were made by two raters masked to ethnicity of the participants reducing observer bias. Although AfricanCaribbean people are heterogeneous in terms of ethnicity, our findings are consistent with previous smaller studies, in finding a raised prevalence of dementia in African-Caribbean participants at a lower mean age. ${ }^{31-33}$ There was no difference in the number of years spent in full-time education between ethnic groups and the duration was similar to that found in the Islington study. ${ }^{31}$ All participants spoke English as their first language and therefore language and education are less likely to have influenced performance on cognitive testing differentially between groups. The significance of socioeconomic status was less clear. Whereas African-Caribbean participants were nearly $50 \%$ more likely to own their own homes than White participants, the majority fell into the lowest socioeconomic groups. Socioeconomic status according to occupation (NS-SEC), although not a risk factor for dementia per se, might be a 'proxy' for other covariates such as educational level, general health, smoking or diet. However, this may be untrue for many African-Caribbean people, who migrated to UK to fill relatively unskilled jobs for their level of education and social status. We imputed data for 22 participants with missing NS-SEC in the regression analysis, so as to be able to include all participants, but this did not change the model and so we do not think it biased the results.

The two-stage (screening/diagnostic) design resulted in the loss of three participants (6\%) who failed to complete the second phase. All three were African-Caribbean, potentially biasing the results and leading to a small underestimation of dementia prevalence in this group. Additionally, some participants may have falsely screened negative at the first phase and been missed.

Although prevalence is difficult to estimate, our findings are in line with the existing literature. For example, our estimate for dementia prevalence in White UK-born participants aged over 60 years of $6.9 \%$ is only marginally higher than the Delphi consensus study estimate for Western Europe of 5.4\%. ${ }^{1}$ When adjusted for age, it is also similar to the Islington study estimate of $10 \%$ in UK-born participants aged over 65 years $^{32}$ and the Caerphilly Prospective Study estimate of $6.1 \%$ in a cohort of men aged 65-84 years. $^{34}$

With regard to African-Caribbean people, our estimate of $9.6 \%$ in participants over 60 years, corresponded closely to the Islington study estimate of $17.3 \%$ in those over $65 .^{31}$ Although their sample is not strictly comparable to ours, in that it was a mixed group of Black African and Caribbean people, the majority ( $>60 \%$ ) were of African-Caribbean origin. The findings are less similar to other cross-sectional studies in that our estimate of dementia prevalence was considerably higher than the Liverpool study $^{32}(8 \%)$ and lower than a South London pilot study ${ }^{33}$ (34\%) both in participants over 65 years.

Proportionally more participants met the DSM-IV than the ICD-10 criteria for dementia. This was because unlike DSM-IV, ICD-10 requires both a minimum period for symptoms (6 months) and a reliable informant history. Similarly, a lack of informant history may have contributed to five participants with cognitive impairment but no evidence of functional impairment being categorised as having mild cognitive impairment. They were excluded from the dementia category in the regression analysis but including them did not change the result. In addition, a lack of detailed informant history made it impossible to specify a dementia subtype in six participants. The numbers given a subtype diagnosis were small and the data generated are preliminary and should be interpreted with caution because of the small numbers and lack of physical investigations. The majority, 69\%, of all participants were diagnosed with Alzheimer's disease according to at least one set of criteria. This is close to the recent Dementia UK report estimate of $62 \% .{ }^{35}$ However, the rates varied considerably depending on the criteria used; $39 \%$ met the ICD-10 criteria, 56\% DSM-IV criteria and 69\% the NINCDSADRDA criteria (possible or probable). The overall prevalence of vascular (or mixed) dementia by any criteria (28\%) was also close to the Dementia UK report estimate of $27 \%$. Of note, nine of the ten participants diagnosed with vascular dementia were African-Caribbean. None met the criteria for NINDS-AIREN 
'probable' criteria, partially because very few participants had a complete set of physical investigations including neuroimaging.

\section{Clinical and policy implications}

Both primary and secondary care clinicians should be aware that dementia may occur more commonly and at younger ages in African-Caribbean than White people. It also supports the move towards 'needs based' rather than age-determined health and social services. Also, when screening for dementia or assessing cognitive performance in African-Caribbean people the culturally specific version of the MMSE should be used. ${ }^{15}$ It suggests that the use or development of acceptable, valid and reliable tests for the screening and diagnosis of dementia in other BME groups would be desirable.

Both primary and secondary prevention may be especially relevant for African-Caribbean people in terms of vascular risk factors. Timely identification and effective treatment of hypertension could be extremely important in reducing rates of dementia. This is in keeping with UK current government policy, and effective management of hypertension is one of the Quality and Outcomes Framework (QOF) indicators for general practitioners (www.nhsemployers.org).

\section{Unanswered questions and future research}

Our study provided no information as to whether the higher prevalence of dementia in African-Caribbean people is as a result of a higher incidence or to living longer with the disorder. Longitudinal studies are desirable; both to estimate the incidence of dementia and to further investigate putative risk factors. Such studies should consider the subtypes of dementia, as well as the association with education levels, current hypertension or a history of hypertension and its adequate treatment. Other vascular risk factors should also be considered. This may provide more evidence as to the potential of controlling hypertension to prevent Alzheimer's disease or vascular dementia. In addition, we have not explored the role of the significance of social adversity, including socioeconomic deprivation, racism, low social capital and living in areas of low ethnic density. In particular, the first of these is known to be associated with hypertension. ${ }^{10}$ These sources of psychological 'stress' have been hypothesised as a risk factor for other mental illnesses, ${ }^{11,12}$ although it is not yet clear what effect this may have on the rates of dementia.

Simon Adelman, MRCPsych, MSC, PhD, Martin Blanchard, MRCPsych, MD, Department of Mental Health Sciences, University College London; Greta Rait, MD, MSC, MRCGP, MRC General Practice Research Framework, London; Gerard Leavey MSC, PhD, Northern Ireland Association for Mental Health (NIAMH) \& University of Ulster, Belfast; Gill Livingston, FRCPsych, MD, Department of Mental Health Sciences, University College London, UK

Correspondence: Simon Adelman, Department of Mental Health Sciences, UCL, 67-73 Riding House Street, 2nd Floor, Charles Bell House, London W1W 7EJ, UK. Email: simon.adelman@candi.nhs.uk

First received 9 Sep 2010, final revision 21 Dec 2011, accepted 23 Feb 2011

\section{Funding}

The study was funded by the Medical Research Council and sponsored by University College London.

\section{References}

1 Ferri $\mathrm{CP}$, Prince M, Brayne C, Brodaty H, Fratiglioni L, Ganguli M, et al Global prevalence of dementia: a Delphi consensus study. Lancet 2005; 366: $2112-7$.
2 Tang MX, Cross $P$, Andrews $H$, Jacobs DM, Small S, Bell K, et al. Incidence of $A D$ in African-Americans, Caribbean Hispanics, and Caucasians in northern Manhattan. Neurology 2001; 56: 49-56.

3 Demirovic J, Prineas R, Loewenstein D, Bean J, Duara R, Sevush S, et al. Prevalence of dementia in three ethnic groups: the South Florida program on aging and health. Ann Epidemiol 2003; 13: 472-8.

4 Krishnan LL, Petersen NJ, Snow AL, Cully JA, Schulz PE, Graham DP, et al. Prevalence of dementia among Veterans Affairs medical care system users. Dement Geriatr Cogn Disord 2005; 20: 245-53.

5 Heyman A, Fillenbaum G, Prosnitz B, Raiford K, Burchett B, Clark C. Estimated prevalence of dementia among elderly black and white community residents. Arch Neurol 1991; 48: 594-8.

6 Folstein MF, Bassett SS, Anthony JC, Romanoski AJ, Nestadt GR. Dementia: case ascertainment in a community survey. J Gerontol 1991; 46: M132-8.

7 Auchus AP. Dementia in urban black outpatients: initial experience at the Emory satellite clinics. Gerontologist 1997; 37: 25-9.

8 Adelman S, Blanchard M, Livingston G. A systematic review of the prevalence and covariates of dementia or relative cognitive impairment in the older African-Caribbean population in Britain. Int J Geriatr Psychiatry 2009; 24: 657-65.

9 Skoog I. Antihypertensive treatment and dementia prevention. Lancet Neurol 2008; 7:664-5.

10 Diez-Roux AV, Chamberless L, Merkin SS. Socioeconomic disadvantage and change in blood pressure associated with ageing. Circulation 2002; 106: 7.

11 King M, Coker E, Leavey G, Hoare A, Johnson-Sabine E. Incidence of psychotic illness in London: comparison of ethnic groups. BMJ 1994; 309 : 1115-9.

12 Kirkbride JB, Boydell J, Ploubidis GB, Morgan C, Dazzan P, McKenzie K, et al. Testing the association between the incidence of schizophrenia and social capital in an urban area. Psychol Med 2008; 38: 1083-94.

13 Department of Health. National Standards for Ethnic Group and Related Matters. Department of Health, 2001 (http://www.dh.gov.uk/en/ Publicationsandstatistics/Publications/PublicationsPolicyAndGuidance/ Browsable/DH_5319155).

14 Office for National Statistics. The National Statistics Socio-economic Classification User Manual (2005 edition). Palgrave Macmillan, 2005.

15 Rait G, Morley M, Burns A, Baldwin R, Chew-Graham C, St Leger AS. Screening for cognitive impairment in older African-Caribbeans. Psychol Med 2000; 30: 957-63.

16 Molloy DW, Alemayehu E, Roberts R. Reliability of a Standardized Mini-Mental State Examination compared with the traditional Mini-Mental State Examination. Am J Psychiatry 1991; 148: 102-5.

17 Roth M, Tym E, Mountjoy CQ, Huppert FA, Hendrie H, Verma S, et al. CAMDEX. A standardised instrument for the diagnosis of mental disorder in the elderly with special reference to the early detection of dementia. Br J Psychiatry 1986; 149: 698-709.

18 World Health Organization. The ICD-10 Classification of Mental and Behavioural Disorders: Diagnostic Criteria for Research. WHO, 1993.

19 American Psychiatric Association. Diagnostic and Statistical Manual of Mental Disorders (4th edn, text revision) (DSM-IV-TR). APA, 2000.

20 Petersen RC, Smith GE, Waring SC, Ivnik RJ, Tangalos EG, Kokmen E. Mild cognitive impairment: clinical characterization and outcome. Arch Neurol 1999; 56: 303-8.

21 McKhann G, Drachman D, Folstein M, Katzman R, Price D, Stadlan EM Clinical diagnosis of Alzheimer's disease: report of the NINCDS-ADRDA Work Group under the auspices of Department of Health and Human Services Task Force on Alzheimer's Disease. Neurology 1984; 34: 939-44.

22 Roman GC, Tatemichi TK, Erkinjuntti T, Cummings JL, Masdeu JC, Garcia JH, et al. Vascular dementia: diagnostic criteria for research studies. Report of the NINDS-AIREN International Workshop. Neurology 1993; 43: 250-60.

23 McKeith IG, Dickson DW, Lowe J, Emre M, O'Brien JT, Feldman H, et al. Diagnosis and management of dementia with Lewy bodies: third report of the DLB Consortium. Neurology 2005; 65: 1863-72.

24 McKhann GM, Albert MS, Grossman M, Miller B, Dickson D, Trojanowski JQ. Clinical and pathological diagnosis of frontotemporal dementia: report of the Work Group on Frontotemporal Dementia and Pick's Disease. Arch Neurol 2001; 58: 1803-9.

25 Miles J, Shevlin M. Applying Regression and Correlation: A Guide for Students and Researchers. Sage Publications, 2001.

26 Jorm AF, Korten AE, Henderson AS. The prevalence of dementia: a quantitative integration of the literature. Acta Psychiatr Scand 1987; 76 $465-79$

27 Folstein MF, Folstein SE, McHugh PR. 'Mini-mental state'. A practical method for grading the cognitive state of patients for the clinician. J Psychiatr Res 1975; 12: 189-98. 
28 Parker C, Philp I. Screening for cognitive impairment among older people in black and minority ethnic groups. Age Ageing 2004; 33: 447-52.

29 Johnson MR, Cross M, Cardew SA. Inner-city residents, ethnic minorities and primary health care. Postgrad Med J 1983; 59: 664-7.

30 Richards M. Surveying African Caribbean elders in the community: implications for research on health and health service use. Int J Ger Psychiatry 1996; 11: 41-5.

31 Livingston G, Leavey G, Kitchen G, Manela M, Sembhi S, Katona C. Mental health of migrant elders - the Islington study. Br J Psychiatry 2001; 179: $361-6$.
32 McCracken CF, Boneham MA, Copeland JR, Williams KE, Wilson K, Scott A et al. Prevalence of dementia and depression among elderly people in black and ethnic minorities. Br J Psychiatry 1997; 171: 269-73.

33 Richards M, Brayne C, Dening T, Abas M, Carter J, Price M, et al. Cognitive function in UK community-dwelling African Caribbean and white elders: a pilot study. Int J Geriatr Psychiatry 2000; 15: 621-30.

34 Fish M, Bayer AJ, Gallacher JE, Bell T, Pickering J, Pedro $\mathrm{S}$, et al. Prevalence and pattern of cognitive impairment in a community cohort of men in South Wales: methodology and findings from the Caerphilly Prospective Study. Neuroepidemiology 2008; 30: 25-33.

35 Knapp M. Dementia UK - The Full Report. London School of Economics, King's College London, 2007.

\section{extra Exposure to chemical warfare during the First World War: shell shock poetry of Wilfred Owen}

\section{Menachem Ben-Ezra}

One of the most striking personal accounts of psychological reactions to chemical gas attack during the First World War can be seen in the poem Dulce et decorum est pro patria mori:

( . . . ) Gas! GAS! Quick, boys! - An ecstasy of fumbling

Fitting the clumsy helmets just in time,

But someone still was yelling out and stumbling

And flound'ring like a man in fire or lime. -

Dim through the misty panes and thick green light,

As under a green sea, I saw him drowning.

In all my dreams before my helpless sight

He plunges at me, guttering, choking, drowning.

If in some smothering dreams, you too could pace

Behind the wagon that we flung him in,

And watch the white eyes writhing in his face,

His hanging face, like a devil's sick of sin,

If you could hear, at every jolt, the blood

come gargling from the froth-corrupted lungs

Bitter as the cud of vile, incurable sores on innocent tongues ( . . . )

The symptoms of exposure to poison gases used during the First World War (chlorine or phosgene in most cases) are described in the bodily reaction to these chemicals that affect the lungs, skin and mucous membranes. When the lungs are affected the feeling is of one gasping for air and drowning.

Owen's account meets several symptom clusters of post-traumatic stress disorder in the DSM-IV-TR. Exposure to poison gas attack is considered a traumatic event meeting criterion A. Re-experiencing is presented by an intrusive recollection of the attack via disturbing dreams that haunted the person in the poem. Increased arousal is described in the tone and description of the reactions to the gas attack along with sleep disturbances.

It should be noted that Owen had experienced two more major traumatic events during the First World War: being thrown in the air by the blast of a trenched mortar and landing on the remains of fellow officer, and being trapped for days in an old German dug-out Later on, he was diagnosed as suffering from shell shock and was sent to Craiglockhart War Hospital in Edinburgh. During his time at the hospital, he was influenced by the poet Siegfried Sassoon who had encouraged Owen to explore in his poetry the symptoms of shell shock such as flashbacks, recurrent and repetitive nightmares, and intrusive memories of battle. After returning to his regiment, Owen was killed in action on 4 November 1918 during the crossing of the Sambre-Oise Canal.

Menachem Ben-Ezra, School of Social Work, Ariel University Center of Samaria, Ariel, Israel. 